\title{
INTENÇÃO EDUCACIONAL DA ÉTICA DE TOMÁS DE AQUINO NO CONTEXTO CITADINO NO SÉCULO XIII
}

Tatyana Murer Cavalcante*

Terezinha Oliveira**

RESUMO: O objetivo deste texto é tecer considerações sobre a concepção de ética de Tomás de Aquino (1224-5?/1274), a partir da relação entre produção do conhecimento e transformações sociais. Selecionamos para análise a questão "As consequências dos atos humanos em razão da bondade e da malícia", oriunda da obra principal do autor, a Suma de Teologia. Faremos este debate à luz de estudiosos da contemporaneidade que tratam do tema, com destaque especial para Le Goff, Lauand e Oliveira. Compreendemos que a elaboração de Tomás de Aquino, gestada na e para a cidade, afirmava a necessidade do conhecimento e do ensino de virtudes orientadas para as relações sociais que implicavam a responsabilidade pessoal. Consideramos que este estudo pode nos apontar caminhos para o debate sobre a ética na atualidade.

Palavras-chave: História da Educação. Ética e Educação. Tomás de Aquino.

\section{THE EDUCATIONAL INTENTION IN THE ETHICS OF THOMAS AQUINAS, AND ITS URBAN CONTEXT, IN THE THIRTEENTH CENTURY}

ABSTRACT: The goal here is to consider the ethical conception reasoned out by Thomas Aquinas (1224-5?/1274), beginning with the relationship between knowledge production and social transformation. We selected, for analysis, the topic: "The consequences of human actions on grounds of goodness and malice" from the author's main work, the Summa of Theology. We will stage this debate in the light of contemporary scholars dealing with the issue, paying attention, in particular, to Le Goff, Lauand and Oliveira. It is our understanding that the ideas developed by Thomas Aquinas conceived of, both in and for the city, confirmed the need for knowledge of, and teaching of, virtues; such virtues being oriented towards social relationships that have personal responsibility implicit in them. We consider that this study may point the way to a debate about ethics suited to the present day.

Keywords: History of Education. Ethics and Education. Thomas Aquinas.

* Doutoranda em Educação, com bolsa CAPES, do Programa de Pós-graduação em Educação da Universidade Estadual de Maringá (UEM) e pesquisadora do GTSEAM. E-mail: tayonca@gmail.com

** Doutora em História pela Universidade Estadual Paulista Júlio de Mesquita Filho; Professora associada nível C da Universidade Estadual de Maringá e bolsista produtividade em pesquisa do Conselho Nacional de Desenvolvimento Científico e Tecnológico (CNPq) - nível 2. E-mail: toliveira@uem.br 


\section{Introdução}

Ética é um tema em evidência na atualidade. O debate vem à tona na mídia, a cada notícia de violência, vandalismo, má utilização de dinheiro público, apropriação privada de bens públicos, entre outros temas. À sociedade brasileira se coloca a necessidade de refletir sobre a ética e se impõe à universidade, de maneira especial, a responsabilidade por essa reflexão.

Assim como nos demais campos do saber, a Educação também se propõe debater a ética. Essa reflexão, tão fundamental aos nossos dias, é reincidente. Em diferentes sociedades, os homens se dispuseram a compreender, a estabelecer os limites e as ações necessárias para a convivência comum. É nesse sentido que consideramos importante investigar, na História da Educação, o conhecimento que a humanidade nos legou. Compreendemos, entretanto, que algumas situações históricas podem contribuir mais incisivamente nessa reflexão, como o nascimento da universidade, na vida citadina do século XIII.

A cidade ${ }^{1}$ medieval alargou as possibilidades da vivência humana, pela multiplicidade de papéis sociais que impunha. Os citadinos precisaram organizar-se de forma coletiva. Ainda no século XII, eles criaram a Corporação de Ofício, sistematizando o trabalho. Naquela nova realidade, os homens reconsideraram suas proposições teóricas, para compreenderem-se no espaço dessas novas relações, motivo pelo qual conhecimentos de diferentes campos do saber eram questionados, como direito, medicina, política, teologia e educação. A exemplo dos demais campos de trabalho, no século XIII, conhecimento e ensino ganharam uma nova instituição, a universidade, local privilegiado de debate teórico daquela sociedade. No universo que se abria, era necessário redefinir regras de convivência e ideais sociais, também originados e debatidos no seio da universidade.

É sob a perspectiva dessas transformações que, no decorrer do texto, ponderaremos a elaboração da concepção de ética em Tomás de Aquino (1224-5?/1274), teólogo dominicano e mestre universitário, reconhecido como um dos principais ícones da literatura escolástica. Por esse motivo, consideramos essencial debater a produção desse autor na ambiência citadina do século XIII.

Se, por um lado, alguns fatores da experiência humana podem ser reconhecidos como reincidentes, é fundamental lembrarmos que essa 
experiência é também ressignificada do ponto de vista teórico. Assim, os dois principais termos envolvidos na elaboração desse artigo, ética e educação, não podem ser tomados do mesmo modo no século XIII e no XXI. Ética, em nosso tempo, diz respeito à avaliação normativa de ações e de caráter de indivíduos ou grupos sociais (O’NEILL, 1996, p. 278), distinguido-se da moralidade, que implica um conjunto de considerações ao modo mais correto de se bem viver numa sociedade, no sentido descritivo ou prescritivo (CRISP, 1996, p. 483). A distinção das instâncias éticamoralidade é uma criação da Modernidade (O’NEILL, 1996, p. 278). Desse modo, ao vislumbrarmos um período histórico anterior à Modernidade, como o século XIII, é necessário considerar ética e moralidade como indissociáveis. Nesse sentido, não era a pergunta "como devo agir?" posta no debate ético, mas sim a pergunta "que pessoa eu devo ser?"’ impunha-se à elaboração em questão.

Quanto ao segundo elemento - a educação - também é necessário considerar que embora ela não tenha perdido o caráter de socialização, a partir da Modernidade ela está mais associada a processos do ensino preferencialmente escolares e tem, mais recentemente, sofrido uma sistematização como saber científico (PATEMAN, 1996, p. 233). Assim, muito embora os homens do passado não tenham se furtado de refletir sobre a educação e o ensino, esse estudo se configurava como parte de um debate mais amplo, vinculado à ética, à sociabilidade e ao caráter e, no caso da elaboração filosófica cristã medieval, a uma ética religiosa. Ao tomarmos a obra de Tomás de Aquino é importante também compreendermos que os aspectos educacionais eram parte de um estudo filosóficoteológico, este sim muito bem delineado pelo autor. Por esses motivos, não nos é possível encontrar, na obra tomasiana, instruções sistematizadas sobre o fazer educativo, tal como encontraríamos se tomássemos nossos contemporâneos, sendo possível apenas traçar, a partir da análise da obra em seu contexto, as intenções educativas do autor.

Para refletirmos sobre a produção de Tomás de Aquino no espaço citadino do século XIII, selecionamos para análise um texto do autor, a questão "As consequências dos atos humanos em razão da bondade e da malícia” (TOMÁS DE AQUINO, ST, I I II ${ }^{a c}$, q. 21) ${ }^{3}$, oriunda da obra principal do mestre, a Suma de Teologia ${ }^{4}$. Essa questão é constituída de quatro partes, nomeadas artigos, e cada um deles inicia-se por meio de indagação. A análise que empreendemos tem como ponto de partida a 
própria estrutura do texto do autor, ou seja, partiremos das perguntas elaboradas por ele para organizar a exposição. Entretanto, dividimo-la em três partes. A primeira delas, nomeada "Os atos humanos e os citadinos no século XIII", refere-se à questão proposta no primeiro artigo: "O ato humano, enquanto bom ou mau, tem razão de retidão ou de pecado?", em que apresentaremos o autor e alguns elementos essenciais de seu tempo, de forma a introduzir a relevância do debate teórico sobre os atos humanos. A segunda parte, "Responsabilidades pessoais e consciência de grupo" se refere à questão proposta no segundo artigo, se o ato humano tem razão "de louvável ou de culpável”, em que apresentaremos a biografia do autor e aprofundamos a exposição de alguns elementos históricos essenciais à noção de bem comum. Finalmente, a terceira parte, "Conhecimento, ensino e responsabilidade", está relacionada às questões propostas no terceiro e no quarto artigos, se os atos humanos têm razão de "mérito ou demérito" entre os homens e diante de Deus. Nesta parte, aprofundaremos a concepção de ética de Tomás de Aquino, pautada na noção de homem como totalidade corpóreo-mental, social e espiritual. As duas primeiras partes nos auxiliam a cercar a concepção ética do autor no seio do século XIII, enquanto a última nos permite um questionamento sobre a possibilidade de este estudo nos auxiliar em relação à ética no presente.

Para realizarmos este estudo, nós nos basearemos em diferentes obras da historiografia contemporânea, notadamente - mas não exclusivamente - a de Jacques Le Goff ${ }^{5}$, reconhecido medievalista francês, bem como de Jean Lauand e Terezinha Oliveira, pesquisadores brasileiros que se dedicam ao estudo da História da Educação Medieval.

\section{Os atos humanos e os citadinos no século XIII}

"O ato humano, enquanto bom ou mau, tem razão de retidão ou de pecado?" Assim Tomás de Aquino lançava a primeira das quatro perguntas da questão: "As consequências dos atos humanos em razão da bondade e da malícia” (TOMÁS DE AQUINO, $S T$, $\mathrm{I}^{\mathrm{a}} \mathrm{II}^{\mathrm{ae}}$, q. 21, a. 1). Essa indagação permite-nos apresentar os elementos essenciais da elaboração da ética do Aquinate ${ }^{6}$. Em primeiro lugar, por seu objeto próprio, o "ato" humano. Em segundo, pelo tratamento teológico dispensado ao 
tema. Em terceiro e último, porque a escrita é iniciada por uma pergunta, em vez de explicitar uma afirmação.

Como anunciamos na introdução, Tomás de Aquino foi teólogo dominicano e mestre universitário. Os intelectuais que se dedicam a estudá-lo indicam que aquele mestre viveu integralmente para a evangelização e para o ensino (TORRELL, 1999; LAUAND, 1999; OLIVEIRA, 2005). Confiramos como Le Goff descreve o Mestre de Aquino:

Tomás de Aquino é o escolástico que deixou a maior influência no pensamento europeu até hoje. Italiano, da pequena nobreza, que morou muitas vezes em Paris como estudante e depois como professor, também em Orvieto, em Roma e em Nápoles, foi um professor da moda que atraía e entusiasmava os estudantes, e um pensador audacioso que provocou a hostilidade de numerosos colegas e de certos prelados influentes. É o tipo do intelectual europeu, sedutor e contestado, que iluminava e perturbava ao mesmo tempo os meios intelectuais e religiosos (LE GOFF, 2007, p. 188).

Este autor apresenta o dominicano como pensador atuante e destemido, que se posicionou frente aos debates teóricos, ou seja, como um homem de ação. $\mathrm{O}$ medievalista francês não está sozinho ao afirmar a força da atuação do Aquinate em seu tempo. Segundo Lauand (1999), o "Doutor Angélico", como também ficou conhecido, viveu plenamente o século XIII, especialmente quanto às suas tensões e aos seus desafios. Segundo o autor:

Os cinqüenta anos da vida de Tomás de Aquino (1225-1274) estão plenamente centrados no século XIII, e não só do ponto de vista cronológico: todas as significativas novidades culturais desse tempo mantêm estreita relação com sua vida e lutas. Ao contrário do clichê que o apresenta como uma época de paz e equilíbrio harmônico, esse século é um tempo de agudas contradições, tanto no plano econômico e social como no do pensamento (LAUAND, 1999, p. 4-5).

As palavras de Lauand nos auxiliam a traçar os caminhos que percorremos ao refletir sobre o texto do Aquinate: o dominicano era, antes de tudo, um homem do século XIII. O debate sobre os atos humanos desse autor precisa ser compreendido como elaboração de um pensador citadino que buscou, no conhecimento disponível em seu contexto, auxílio para a reflexão sobre os conflitos que a sua época apresentava. É, pois, em virtude do comprometimento do autor com o seu tempo e com 
sua ambiência que devemos analisar as características da produção de sua obra.

Segundo Le Goff, o século XIII é considerado o apogeu do Ocidente medieval (2007, p. 143). Para esse autor, naquela época, se firmaram a personalidade e a nova força da cristandade, pela qual se impôs um modelo "europeu". Le Goff afirma ainda que esse êxito se verifica em quatro campos: o crescimento urbano, a renovação do comércio e a promoção dos mercadores, a expansão do saber e, por fim, um fator que "sustenta e alimenta" os outros três: a criação e a extraordinária difusão das novas ordens religiosas, as ordens "mendicantes".

Retomemos as palavras de Lauand (1999). Se, como afirma Le Goff, o século XIII é considerado o apogeu do Ocidente medieval, esse não foi um tempo de paz, mas de agudas contradições. As novas possibilidades para a vida humana eram orientadas pelas cidades e se contrapunham às tradições da vida social.

Compreendemos, como Le Goff, a centralidade das cidades ${ }^{7}$ no forjar de uma nova sociedade. Numa obra dedicada especialmente ao apogeu das cidades medievais, esse autor afirma que, sob a égide da Igreja, na cidade se adaptava uma nova sociedade. "As cidades são uma das principais manifestações e um dos motores essenciais dessa culminação medieval" (LE GOFF, 1992, p. 1).

O autor observa também que os séculos XI e XII correspondem ao período de desenvolvimento "selvagem" das cidades, mas a sua consolidação efetiva ocorreria a partir da segunda metade do século XII e durante o século XIII. Para Le Goff, o termo que melhor exprime a realidade ideológica da cidade é universitas (corporação), a coletividade formada pelos habitantes. A comunidade urbana é mais do que a soma do conjunto de indivíduos, ela é "[...] a consciência de grupo que se afirma na ação e na oposição” (LE GOFF, 1992, p. 81).

Por esse motivo é essencial, ao considerarmos "atos humanos" em Tomás de Aquino, compreendermos a especificidade histórica do debate. Ao Aquinate não interessava simplesmente investigar os atos humanos como conceitos universais, mas sua caracterização segundo a tomada de consciência da comunidade urbana. Nesse sentido, é necessário que investiguemos o caráter teológico da abordagem tomasiana.

Numa obra dedicada ao estudo historiográfico da Filosofia Medieval (Escolástica), Oliveira (2005) apresenta uma contribuição essen- 
cial para esse debate. Segundo a autora, no surgimento da Idade Média, as condições da existência dos homens os afastavam da forma de viver da Antiguidade e, especialmente, da vida citadina, condições nas quais aqueles homens tinham preocupações e questões que lhes eram próprias. A busca pela verdade, o filosofar medieval, desde o século VI, deslocou-se das academias citadinas para os mosteiros. Em suas palavras:

O mosteiro não é apenas um local de preservação da cultura. Acima de tudo, nele preserva-se a vida a partir de uma nova perspectiva, a do cristianismo. Assim, não é só o local, o espaço que é novo. Também o que será ensinado e vivido é novo. Trata-se de uma nova filosofia, imbuída antes de tudo pelo princípio da conversão (OLIVEIRA, 2005, p. 18).

Ao propor o mosteiro como espaço privilegiado de uma nova filosofia, a autora indica uma posição que nos é cara: ao contrário do lugar comum que apresenta essa instituição como local de preservação da cultura, o mosteiro foi também o local da reflexão, o espaço para o filosofar, em uma sociedade em processo de "ruralização" e "embrutecimento".

Destacamos, anteriormente, apoiando-nos em Le Goff (2007), que a expansão do saber foi um dos fatores essenciais ao êxito urbano. Comungamos da ideia que ele sustenta de que a expansão do universo escolar ocorreu no ambiente urbano com bastante força a partir do século XII. Entretanto consideramos relevante o fato de que, nos seis séculos que precederam esse fenômeno, a elaboração do conhecimento filosófico e seu ensino aconteceram privilegiadamente em mosteiros. Além disso, grande parte das escolas urbanas do século XII ainda era ligada às catedrais (catedralícias) ou aos mosteiros. Essa condição é essencial para que retomemos o terceiro elemento à nossa análise, ou seja, o fato de Tomás de Aquino principiar a exposição de suas formulações, sempre, por meio da indagação.

Poderíamos simplesmente afirmar que essa era a forma preferida dos escritos no século XIII, no entanto, essa convenção expressa uma realidade que se impunha àqueles homens. Se considerarmos a Suma de Teologia de Tomás de Aquino como exemplo, verificaremos que essa obra foi nomeada por sua forma e por seu objeto. Esse estilo literário (a summa), que pretendia tratar o necessário de cada disciplina, foi remodelado no século XIII. Do anterior "resumo rápido", transformou-se em exame minucioso do conteúdo essencial de cada ciência. As summas pas- 
saram a organizar os temas em questões, e estas, em artigos. Cada artigo era composto tendo como corpus uma pergunta de duas séries de argumentos que se contrapunham, seguidas por uma resposta do autor e, em geral, concluído por refutações individuais à primeira série de argumentos (KENNY; PINBORG, 1997).

No novo molde, as summas eram desdobramentos das coleções de quaestio disputata, muito comuns no século XIII e herdeiras da tradição medieval. Confiramos as palavras de Le Goff, autoridade suficiente para fundamentar nossa compreensão sobre o desenvolvimento da questão disputada:

Seria presunçoso pretender definir em poucas linhas o método escolástico. A evolução primordial foi a que levou da lectio à quaestio e da quaestio à disputatio. O método escolástico é, em primeiro lugar, a generalização do velho procedimento, empregado notadamente em relação à Bíblia, das quaestiones e responsiones, questões e respostas. Mas colocar problemas, pôr os autores "em questões" (no plural), levou a que fossem colocados "em questão" (no singular). Neste primeiro momento, a escolástica foi o estabelecimento de uma problemática. Passou em seguida a ser um debate, a "disputa", e aqui a evolução consistiu em que, ante o puro argumento de autoridade, o recurso à razão ganhou importância crescente. Enfim, a disputa acabava com uma conclusio, dada pelo mestre. Sem dúvida tal conclusão podia sofrer com limitações pessoais daquele que a pronunciava, e como os mestres universitários tendiam a colocar-se eles próprios como autoridades, a conclusão podia ser fonte de uma tirania intelectual. Mas mais do que estes abusos, o que importa é que ela constrangia o intelectual ao engajamento. Ele não podia contentar-se de apenas colocar em questão, mas devia comprometer-se. No extremo do método escolástico estava a afirmação do indivíduo na sua responsabilidade intelectual (LE GOFF, 2005, p. 346. Grifos nossos).

Ao situarmos a Suma de Teologia do Mestre de Aquino no contexto de sua produção e compreendermos, como Le Goff, que essa forma de escrita implicava o comprometimento intelectual, temos uma excelente motivação para considerar que a realidade impunha aos homens a organização dos estudos a partir da indagação e da dúvida.

A obra à qual o Aquinate dedicou - entre outras atividades - os últimos sete anos de sua vida (1266/73 - TORRELL, 1999, p. 388-389), visava ao conhecimento de Deus. Todavia, o objetivo principal da obra não era o conhecimento de Deus em si mesmo, mas ele enquanto princípio e fim das criaturas e, especialmente, apreciar como o movimento humano possibilitaria atingir esse fim. Nas palavras do autor: 
O objetivo principal da doutrina sagrada está em transmitir o conhecimento de Deus não apenas quanto ao que ele é em si mesmo, mas também enquanto é o princípio e o fim das coisas, especialmente da criatura racional, como ficou demonstrado. No intento de expor esta doutrina, havemos de tratar: 1. de Deus; 2. do movimento da criatura racional para Deus; 3. do Cristo, que, enquanto homem, é para nós o caminho que leva a Deus (TOMÁS DE AQUINO, ST, Ia , q. 2, prólogo).

Ao apresentar as possibilidades do caminhar humano, o autor colocou como ponto de partida (e de chegada) um objetivo religioso, a bem aventurança. Mas, ao debater especialmente os movimentos, fixou o olhar nos atos concretos. O mestre Tomás precisava compreender como os homens atingiriam esse objetivo na realidade do século XIII. Ora, a realidade, para o citadino do século XIII, se apresentava de maneira diversa do que poderia se verificar na tradição teológica/ filosófica consolidada por seis séculos. A complexidade da vida na cidade expunha a necessidade de se reconsiderar as posições teóricas. Dessa forma, ao investigar minuciosamente o conhecimento disponível, era preciso contrapor diferentes compreensões sobre cada tema. Que caminhos poderiam ser mais adequados aos cristãos na nova vida que se apresentava? Seria possível equilibrar valores celestes e terrestres? Como?

Em $A$ bolsa e a vida, Le Goff, afirma: "O século XIII é a época em que os valores se tornam mais terrenos” (2004, p. 65). As condições gestadas nas cidades propiciaram o debate sobre a validade do desejo e dos usos dos bens terrenos sob as novas condições.

Nesse sentido, podemos compreender a importância dos mercadores para o que o Le Goff chama de "apogeu" do Ocidente medieval. Ao mesmo tempo em que concorreram para tornar mais terrenos os valores, os mercadores levantaram problemas com a difusão do dinheiro na economia e na sociedade (2007, p. 143). Além disso, contribuíram para a abertura do horizonte intelectual medieval. Em outro texto, afirma o mesmo autor:

Filha do tempo, a verdade o é também do espaço geográfico. As cidades são placas giratórias da circulação dos homens, responsáveis tanto pelas idéias como pelas mercadorias, são os pontos de troca, os mercados e as encruzilhadas do comércio intelectual. Nesse século XII em que o Ocidente quase só pode exportar matérias-primas - ainda que esteja nascendo o desenvolvimento têxtil -, os produtos raros, os objetos valiosos vêm do Oriente, de 
Bizâncio, de Damasco, de Bagdá, de Córdoba. Com as especiarias e a seda, os manuscritos trazem ao Ocidente cristão a cultura greco-árabe (LE GOFF, 2006, p. 37).

Ao munirem o Ocidente de mercadorias e ideias, os mercadores contribuíam para a dessacralização dos valores. Mas, segundo o medievalista francês, juntamente com a atuação dos mercadores, o surgimento de outra categoria profissional também foi elemento essencial para a transformação do saber naquela sociedade: os "intelectuais" (categoria que congrega os profissionais do saber). Afirma:

Homem de ofício, o intelectual tem consciência da profissão a assumir. Reconhece a ligação necessária entre a ciência e o ensino. Não pensa mais que a ciência deve ser entesourada: está persuadido de que deve ser posta em circulação. As escolas são oficinas de onde são exportadas as idéias, como mercadorias (LE GOFF, 2006, p. 88).

A especificidade da questão do saber é muito relevante. Mais uma vez (a exemplo do início da Idade Média) o conhecimento não mudara apenas de endereço. Ao sair do mosteiro e do campo e instalar-se nas escolas das cidades, alteraram-se também as categorias sociais, os homens que conheciam e ensinavam, seus modos de viver, seus ideais e objetivos com os estudos. O universo escolar reorganizou os conhecimentos. Ainda no século XII, as escolas de Paris começaram a destacar-se:

Paris deve sua fama primeiro à explosão do ensino teológico, que está no topo das disciplinas escolares, porém logo, mais ainda, ao ramo da filosofia que, usando plenamente a contribuição aristotélica e o recurso ao raciocínio, faz triunfar os métodos racionais do espírito: a dialética (LE GOFF, 2006, p. 44).

Como os demais ofícios, essa nova categoria profissional tendeu a organizar-se em corporação, em universitas. Segundo Le Goff, o movimento corporativo foi favorecido pela reabilitação do trabalho, uma vez que a ideia de trabalho-castigo foi lentamente substituída pela ideia de trabalho-útil-aos-homens, capaz de conduzir à salvação. Assim, "Entre meados do século XII e meados do XIII, duas novas categorias de homens se introduzem no mundo dos ofícios urbanos e se apresentam, se justificam como trabalhadores: o mercador e o intelectual" (LE GOFF, 1992, p. 102). 
Observamos anteriormente que a complexidade da vida provoca a necessidade de reinterpretar a existência. Nesse sentido, a organização das instituições e a elaboração de saberes são essenciais à transformação social, que não podem ser caracterizadas por uma evolução simples, mas por uma tensão entre ideais desejados por seus componentes. Ao falar sobre as origens das corporações, Le Goff afirma que suas motivações foram ambíguas. Segundo ele: "A organização corporativa é uma espécie de polícia no interior do ofício e entre ofícios, onde entram os citadinos e os estrangeiros. Ela é também o lugar da solidariedade profissional"” (LE GOFF, 1992. p. 99).

Quanto ao nascimento da corporação dedicada ao conhecimento e ao ensino, afirma Le Goff:

Essas escolas [as escolas urbanas] receberam, no final do século XII, o nome de studium generale, escola geral, que indicava ao mesmo tempo um status superior e um ensino de tipo enciclopédico. Essas escolas, que se situavam no ambiente do grande movimento de organização dos ofícios nas cidades constituíram-se em corporação como os outros ofícios e tomaram o termo universidade, que significava corporação, e apareceu pela primeira vez em 1221 em Paris ${ }^{9}$, para designar a comunidade de mestres e de estudantes parisienses (universitas magistrorum et scholarium) (LE GOFF, 2007, p. 173).

Segundo Verger (1999), entre 1180 e 1220 estabeleceu-se em Paris uma corporação universitária que nasceu com dupla tendência. De um lado, afirmar-se eclesiástico, de outro, ostentar uma tendência laicizante já presente nas escolas. Para o autor, o estabelecimento da universidade não significou a conquista de uma concordância sobre o conhecimento, uma vez que, em seu interior, as duas posturas distintas rivalizavam, em debates institucionais e doutrinais. Forjar-se com caráter eclesiástico poderia afastar a corporação de seus interesses por conhecimentos e ensinos laicos. Entretanto, em 1231, a Universidade de Paris completou sua sujeição à jurisdição eclesiástica, com a Bula Parens Scientiarum, fato que, por aproximar a instituição da Igreja, reforçou sua autonomia. Isso foi possível porque uma vez que ela foi atrelada ao papado - poder geral e mais distante -, a universidade manteve-se afastada dos poderes locais que, por sua proximidade, poderiam causar-lhe influência mais decisiva. A partir de então, a Universidade de Paris tornou-se a maior instituição da cristandade medieval. Por sua relação com o Papado, a instituição destina- 
da ao saber diferiu-se das demais corporações. Mas os conflitos no interior da instituição permaneceram durante todo o século XIII, motivados pela integração das ordens mendicantes, pela abertura do ensino à totalidade dos textos aristotélicos (VERGER, 2001) ou mesmo pelas discórdias entre Franciscanos e Dominicanos (OLIVEIRA, 2005).

Desse modo, a dupla tendência da universidade expressava as duas tendências da sociedade: a terra ou o céu? Naquela situação, afinal, o ato humano, enquanto bom ou mal, teria razão de retidão ou pecado? Confiramos a resposta do Mestre de Aquino:

Para os que agem pela vontade [os homens], a regra próxima é a razão humana e a regra suprema, a lei para o fim segundo a ordenação da razão e da lei eterna, será reto; quando porém, se desvia dessa retidão, se diz que há pecado. Dessas premissas evidentemente se conclui que todo ato voluntário é mau porque se afasta da ordenação da razão e da lei eterna e que todo ato bom concorda com razão e a lei eterna. Daí se segue que o ato humano pelo fato de ser bom ou mau, tem a razão de retidão ou de pecado (TOMÁS DE AQUINO, ST, $\mathrm{I}^{\mathrm{a}} \mathrm{II}^{\text {ae }}$, q. 21, a. 1. c. Grifos nossos).

Como esperávamos, o Aquinate avaliava os atos humanos numa perspectiva teológica, celeste. Entretanto, ao apontar a razão humana como regra próxima, abria o caminho para a consideração filosófica, terrestre. É nesse sentido que Le Goff afirma: “[...] a escolástica pode ser considerada como o estabelecimento e a justificação de uma concórdia entre Deus e o homem" (2007, p. 185). Os artigos seguintes nos auxiliarão a aprofundar o terreno da concórdia sugerida por Le Goff, na discórdia do século XIII.

\section{Responsabilidades pessoais e consciência de grupo}

"O ato humano, enquanto bom ou mau, tem razão de louvável ou culpável?” (TOMÁS DE AQUINO, ST, I I II gunta sob a qual o autor inseriu o segundo artigo da questão.

Se, no artigo anterior, o Mestre de Aquino abriu espaço para a consideração filosófica para a razão humana, neste, tratou, especificamente, do alcance da responsabilidade pessoal pelos atos cometidos. Anunciamos anteriormente, segundo Le Goff, que a comunidade urbana 
é a consciência de grupo (1992) e que o "intelectual" tem consciência da profissão a assumir (2006). Para que compreendamos o comprometimento intelectual no século XIII, é necessário que nos voltemos à biografia do Aquinate.

Segundo Torrell (1999, p. 1-12), Tomás de Aquino nasceu na província de Aquino (1224-5?), destinado à vida religiosa, motivo pelo qual foi entregue como oblato ao Mosteiro Beneditino de Monte Cassino, com cerca de seis anos de idade. Depois, entre 1239 e 1244, o Aquinate estudou Artes Liberais em Nápoles, situação na qual conheceu a Ordem dos Dominicanos, à qual se integrou provavelmente em 1244. Segundo o mesmo autor, o ingresso do aplicado estudante nessa ordem desagradou a sua família, que planejava tê-lo como Abade em Monte Cassino, motivo pelo qual o manteve em cárcere privado por cerca de um ano, para dissuadi-lo, entretanto sem alcançar sucesso.

Torrell sustenta que a inclinação para os estudos de Tomás de Aquino seria melhor satisfeita na "nova ordem", baseando-se num argumento da própria Suma de Teologia (ST, $\mathrm{II}^{\mathrm{a}} \mathrm{II}^{\mathrm{ac}}$, q. 188, a. 6): "segundo a teoria por ele [o Aquinate] desenvolvida posteriormente, se é bom contemplar as coisas divinas, melhor ainda é contemplá-las e transmiti-las" (TORRELL, 1999, p. 19). O argumento de Torrell nos remete ao quarto aspecto ao qual Le Goff atribui o apogeu do Ocidente medieval: as ordens mendicantes (2007), expressão da primeira tomada de consciência urbana, no início do século XIII (1992, p. 6).

Ao refletir sobre o nascimento das novas ordens religiosas no século XIII, Le Goff sustenta que os grandes problemas da Igreja, naquele século, eram a reforma gregoriana inacabada, a difusão das heresias, a falta de adaptação a uma sociedade em que a circulação do dinheiro acelerava e que "[...] a cultura monástica ligada a uma sociedade rural não era mais capaz de responder às exigências dos cristãos” (2007, p. 198). Para o autor, a resposta a essas questões veio de algumas personalidades religiosas e leigas que constituíram ordens não monásticas e por isso, de novo tipo, e que foram mais ou menos aceitas pelo papado ${ }^{10}$. Em outro texto, Le Goff esclarece, de um lado, a inadaptação das ordens monásticas à nova realidade e, de outro, as preocupações das duas novas ordens mais importantes do século XIII, Dominicanos e Franciscanos: 
As ordens mendicantes originaram-se do agudo sentimento que tiveram alguns homens e mulheres, principalmente dois, Domingos de Osma e Francisco de Assis, da inadaptação das estruturas e práticas da Igreja às condições de um mundo submetido a uma aceleração da história. Suas motivações conscientes eram sobretudo, para o primeiro, a luta contra a heresia e, para o segundo, a luta contra o dinheiro. Mas cada um desses combates conduzia-os a um mesmo terreno, a cidade. Querendo romper com a tradição monástica que preconizava a instalação na solidão [...] (LE GOFF, 1992, p. 46).

Le Goff argumenta que os homens das novas ordens" não viviam na solidão coletiva dos mosteiros isolados, mas em comunidades no meio das pessoas das cidades, que ajudaram a formar, por meio da pregação e da prática litúrgica. As ordens mendicantes preocupavam-se tanto com a formação dos clérigos quanto com a dos leigos e ensinavam às populações, particularmente urbanas, um cristianismo novo, que adaptava os homens ao progresso da cristandade (LE GOFF, 2007, p. 198-201). Assim, cada mendicante, consciente de fazer parte de um grupo, assumia a responsabilidade pelo ensino.

Le Goff considera as ordens mendicantes tão fundamentais à vida citadina que chega a fundi-las. Em suas palavras:

Insisto em pensar e dizer que há uma Idade Média antes das ordens mendicantes e uma Idade Média depois dessas ordens. Ora, as ordens mendicantes são as cidades! Elas é que primeiro desenvolvem uma verdadeira imagem daquilo que deve ser a cidade, imagem de paz, de justiça, de segurança (LE GOFF, 1998, p. 90. Grifos nossos).

Especificamente quanto à Ordem dos Dominicanos (Pregadores), reconhecida pelo papado em 1217, esta se instalou imediatamente nas grandes cidades ${ }^{12}$ (LE GOFF, 2007, p. 199) e, desde cedo, nas universidades:

Os dominicanos, é verdade, desde a origem procuraram um lugar nas Universidades. O próprio objetivo de seu fundador - a pregação e a luta contra a heresia - os levava em busca de uma sólida bagagem intelectual. Os franciscanos logo chegaram à universidade, acorrendo mais a ela à medida que assumiam uma influência crescente na ordem aqueles que se afastavam, ao menos sob alguns pontos de vista, das posições de São Francisco, hostil, como se sabe, a uma ciência em que via um obstáculo à pobreza, ao despojamento, à fraternidade para os humildes. No início foram bem acolhidos. Em 
1220, o papa Honório III felicita a Universidade de Paris pela acolhida dada aos dominicanos. Depois, houve choques violentos. Na Universidade de Paris, produziram-se os piores deles, entre 1252 e 1290, e particularmente durante os anos de 1252 e 1259 e nos períodos de 1265-1271 e 1282-1290 (LE GOFF, 2006, p. 129).

Pelo próprio objetivo da fundação da Ordem dos Pregadores, exposto por Le Goff, o conhecimento era requerido para solução de um problema real, a luta contra a heresia. Nesse sentido, a presença dessa ordem no seio de uma instituição citadina nova (a universidade), que proporcionava o debate sobre o conhecimento e a difusão de novos saberes, era essencial.

Assim, podemos compreender as palavras de Torrell (1999) quanto à satisfação que a Ordem dos Pregadores proporcionaria a Tomás de Aquino, uma vez que, nela, estudo e ensino eram fundamentais. De fato, nosso autor permaneceu nessa ordem por toda a vida. Pouco depois de se integrar à Ordem dos Dominicanos, ele tornou-se discípulo do mestre Alberto Magno, estudando com ele em Paris (1245-1248) e em Colônia (1248-1252).

Evocamos anteriormente que o Mestre de Aquino viveu intensamente o século XIII (LAUAND, 1999). Uma das grandes características da cultura universitária naquele período foi o internacionalismo dos mestres e discípulos, que se locomoviam entre as instituições de diferentes cidades. Afirma Le Goff:

Na cristandade do século XIII, acostumada pela Igreja ao internacionalismo, as universidades impressionaram por fazer que mestres e estudantes se tornassem itinerantes, indo procurar o saber no estrangeiro e mudando-se facilmente de um país ao outro seguindo a moda ou a reputação de uma universidade ou de um mestre. Os mestres parisienses mais célebres do século XIII foram os dominicanos Alberto Magno, alemão, e Tomás de Aquino, italiano, e o franciscano italiano Boaventura (LE GOFF, 2007, p. 178).

Tomás de Aquino, "mestre parisiense", fez-se professor em Paris, primeiro como Bacharel Sentenciário, entre 1252 e 1256, e, em seguida, como Mestre Regente, lecionando naquela cidade até 1259 . No período seguinte, por cerca de oito anos (1260-1268), realizou suas tarefas de evangelização e ensino fora de Paris, atuando em Nápoles, Orvieto, Roma e Viterbo. O mestre viveu ainda um segundo período de regência 
na Universidade de Paris entre 1269 e 1272. Entre 1272 e 1273, foi regente em Nápoles e faleceu em 1274 (TORRELL, 1999).

Os dois períodos nos quais ele lecionou em Paris (1252-1259 e 1269-1272) foram justamente os mais conturbados daquela universidade, em que seus membros se contrapunham com maior violência (LE GOFF, 2006, p. 199) ${ }^{13}$.

Segundo Torrell (1999), o Mestre geral dos Dominicanos pediu a Alberto Magno que sugerisse um jovem teólogo para ser nomeado bacharel e ensinar em Paris e este sugeriu Tomás de Aquino, que, apesar de jovem (tinha então 27 anos), era considerado por seu mestre suficientemente avançado na ciência e na vida. Desse modo, o Aquinate começou sua carreira docente em Paris, num clima mais tenso, uma vez que, naquela ocasião, mendicantes e seculares acirravam suas diferenças quanto aos rumos que a corporação deveria tomar, o que exigia, diversas vezes, a intervenção do Papado ${ }^{14}$.

Quanto ao retorno de Tomás de Aquino para sua segunda regência em Paris, afirma Torrell:

Não podemos mais do que conjeturar acerca das razões que podem ter motivado a convocação de Tomás a Paris. Para Mandonnet, a crise averroísta era a principal razão; Weispheipl pensa, em vez disso, que se tratava de uma recrudescência da agitação dos seculares contra os mendicantes. Verbeke resume muito bem a situação, acrescentando um terceiro motivo: de retorno a Paris, Tomás deveria "lançar simultaneamente em três frentes: combater os espíritos conservadores da faculdade de teologia, que só viam em Aristóteles um perigo para a fé cristã; em sentido inverso, opor-se ao monopsiquismo averroísta; enfim, fazer a apologia das ordens mendicantes contra os seculares, que queriam excluí-los do ensino universitário" (TORRELL, 1999, p. 213).

Ao retornar a Paris, Tomás de Aquino já iniciara a escrita da Suma de Teologia, da qual tinha traçado o plano geral e escrito a sua primeira parte. Entretanto, a segunda e parte da terceira foram escritas naquela cidade. $\mathrm{O}$ texto que ora utilizamos, retirado da primeira seção da segunda parte da obra, foi elaborado em Paris e sob as condições apresentadas (TORRELL, 1999, p. 174).

Grabmann sustenta que "[...] a segunda parte da Suma teológica considera o homem enquanto ser livre moral e, como tal, podendo tender para Deus como para seu fim último, mas também afastar-se deste fim 
supremo" (1944, p. 137). Segundo o mesmo autor, essa parte da obra se divide em duas, sendo que a primeira seção discute o fim último do homem e os atos humanos como meios para atingir o fim (GRABMANN, 1944, p. 138). A questão específica que trabalhamos situa-se no subconjunto que trata as ações humanas consideradas em si mesmas (GRABMANN, 1944, p. 6-12). Para Grabmann: “[...] os atos próprios do homem [que lhe são exclusivos, no que se diferem dos animais], aqueles que lhe pertencem a titulo de ser espiritual e moral, estão, pois, numa relação muito mais estreita com a felicidade" (1944, p. 139).

Ao explicitarmos as condições nas quais o Mestre de Aquino escreveu o texto em questão, podemos voltar à pergunta do segundo artigo e refletir sobre as responsabilidades pessoais em relação aos atos cometidos. Para analisarmos a complexidade de seu significado, apresentaremos o debate contido nos argumentos iniciais. A primeira linha de argumentos considerados pelo autor assegurava que o ato humano, enquanto bom ou mal, não teria razão de retidão ou pecado. Os dois primeiros argumentos baseavam-se em Aristóteles, sendo que o primeiro afirmava que os pecados (erros) acontecem também nas coisas naturais, que não são louváveis nem culpáveis e, por isso, os erros cometidos pelos homens também não o seriam. Já o segundo igualava os atos morais aos das $\operatorname{artes}^{15} \mathrm{e}$, assim como o artífice não poderia ser culpado por fazer algo mau, mas próprio da profissão, também o ato moral não teria razão de culpável. O terceiro e último argumento, assentado em Dionísio, afirmava que a fraqueza e a impotência excluem ou diminuem a razão da culpa. $\mathrm{O}$ argumento em sentido contrário era também aristotélico e sustentava que as obras das virtudes são louváveis, enquanto as contrárias, culpáveis. Ao resolver o problema, Tomás de Aquino assegurava que os atos especificamente humanos eram louváveis e culpáveis:

[...] um ato é imputado ao que faz quando está sob seu poder, de modo que o domine. Isso é próprio de todo ato da vontade, porque é pela vontade que o homem tem domínio sobre seus atos, como está claro pelo já exposto. Portanto, resulta que o bem ou o mal são razão de louvor ou de culpa somente nos atos voluntários; consequentemente, há um só mal no pecado e na culpa, e nestes se identificam o mal, o pecado e a culpa (TOMÁS DE AQUINO, ST, $\mathrm{I}^{\mathrm{a}} \mathrm{II}^{\mathrm{ac}}$, q. 21, a. 2, c.). 
Em sua resposta geral, o autor afirmou a responsabilidade dos homens por seus atos. Entretanto, a preocupação com os atos humanos, tais quais se davam no século XIII, encontra maior especificidade na resposta do autor ao segundo argumento, uma vez que ela trazia à tona suas preocupações sobre as diferentes categorias desses atos, ao tratá-los como parte de uma relação social mais complexa. Consideremos as palavras do autor:

QUANTO AO 2०, deve-se dizer que a razão se tem diferentemente nas coisas artificiais e nas morais. Nas artificiais, se ordena para um fim particular que é algo pensado por ela mesma. Nas coisas morais, ordena-se para o fim comum de toda vida bumana. Ora, o fim particular ordena-se para o fim universal. Sendo o pecado um afastamento da ordenação para o fim, como foi dito, no ato da arte haverá pecado de dois modos. Primeiro, pelo afastamento de um fim particular intencionado pelo artífice, sendo este um pecado próprio da arte. Por exemplo se o artífice intencionando fazer uma obra boa, a faz má ou intencionando fazê-la má, a faz boa. Segundo, pelo afastamento do fim comum da vida humana, e assim se peca intencionando fazer uma obra má que engane a alguém e a fa\%. Este pecado, porém, não é próprio do artifice enquanto artifice, mas enquanto homem. Por isso, do primeiro pecado o artífice é culpado enquanto artífice, mas do segundo, o homem é culpado enquanto homem, - Na moral em que se considera a ordenação da razão para o fim comum da vida humana, sempre pecado e mal são considerados pelo afastamento da ordem da razão do fim comum da vida humana. Por isso, é culpado deste pecado o homem enquanto homem e enquanto moral (TOMÁS DE AQUINO, ST, I ${ }^{\mathrm{a}} \mathrm{II}^{\mathrm{ae}}$, q. 21, a. 2, ad2m. Grifos nossos).

Essa longa passagem é elucidativa. Em primeiro lugar, destacamos a questão das categorias profissionais. O Aquinate compreendia que, enquanto profissional, o homem podia cometer um erro particular àquela categoria. De maneira semelhante, outros erros se relacionavam às suas categorias profissionais específicas, o que caracteriza a preocupação do Mestre de Aquino com a complexidade da vida social.

Segundo Le Goff, a ideia aristotélica de que o homem é um animal da cidade e, dessa forma, os diferentes componentes do corpo social são necessários e devem ser respeitados para que o bem comum seja possível, fez-se presente na elaboração do Mestre de Aquino. Le Goff afirma: "Assim, para Tomás de Aquino há uma lei dos mercadores que difere da lei dos cavaleiros (alia lex mercatorum... alia militum) [...]" (1992, p. 219). Era em relação à especificidade de cada categoria que se deveriam definir regras próprias e, em função de cada uma, os "pecados"116. 
Em segundo lugar, a citação do Mestre de Aquino também apontava para a responsabilidade do homem enquanto animal, necessariamente, social. Essa característica é essencial à noção de bem comum, essência da ética tomasiana. Mas para compreendermos a "natureza" social do homem, precisamos recorrer a outra parte da obra, na qual o Aquinate discute a virtude da amizade. Em suas palavras: “[...] deve-se dizer que o homem é, por sua natureza, um animal social e deve com honestidade manifestar a verdade aos outros homens, sem o que a sociedade humana não poderia durar" (TOMÁS DE AQUINO, ST, $\mathrm{II}^{\mathrm{a}} \mathrm{II}$ ac q. 114, a. 2, ad1 $\mathrm{m})$. Ora, um ato cometido intencionalmente em detrimento de outro homem era, para o Mestre de Aquino, uma agressão ao fim comum da vida, uma agressão à sociedade, ao homem enquanto totalidade. Essa teia que envolveria o conjunto dos homens, em suas diversas categorias.

\section{Conhecimento, ensino e responsabilidade}

"O ato humano e enquanto bom ou mau tem razão de mérito ou de demérito?" Com essa pergunta o Mestre de Aquino inicia as reflexões do terceiro artigo (TOMÁS DE AQUINO, ST, I $\mathrm{II}^{\mathrm{ac}}$, q. 21, a. 3).

Como no anterior, os argumentos iniciais negavam a responsabilidade humana, mas esse artigo referia-se ao mérito ou ao demérito dos atos humanos, ou seja, o que estava em jogo era o olhar exterior aos atos cometidos, à relação entre os homens. Por esse motivo, também apresentaremos o debate contido nos argumentos iniciais. O primeiro deles afirmava que mérito e demérito ordenavam-se à retribuição e não valeriam para todos os atos humanos, uma vez que diversos deles seriam bons ou maus apenas para a pessoa que os cometia. Já o segundo sustentava que o homem, como senhor de seus atos, não mereceria pena ou prêmio pelo que já era seu. O terceiro e último assegurava que ao adquirir um bem ou fazer um mal para si mesmo, um homem não merecia que alguém o retribuísse ou punisse. Dessa forma, ao fazer um ato bom ou mal, o homem não mereceria recompensa ou punição. $\mathrm{O}$ argumento em sentido contrário, por sua vez, afirmava que se deveria bendizer o justo e maldizer o ímpio, porque para ambos haveria retribuição.

A resposta de Tomás de Aquino explicitava a evidente relação de responsabilidade do indivíduo para com a sociedade. Nela, o autor 
expôs sua noção de totalidade. Para o Aquinate, todas as ações tinham razão de mérito ou demérito porque estavam de acordo com o entendimento da justiça. $\mathrm{O}$ ato humano, ainda que parecesse incidir apenas sobre a pessoa que agia, incidia sobre o conjunto dos homens. Nessa perspectiva, os homens eram responsáveis por si e pelos demais. Observemos sua resposta:

RESPONDO. Mérito e demérito se dizem de acordo com a retribuição que é feita segundo a justiça. A retribuição segundo a justiça é feita a quem agiu para o proveito ou para o prejuízo de outrem. É de se considerar que quem vive em sociedade é parte e membro de toda sociedade. Por isso, quem faz o bem ou o mal para alguém dessa sociedade, isso recai sobre toda a sociedade; por exemplo, aquele que fere a mão, consequentemente fere o homem. Portanto, se alguém faz o mal ou o bem para uma outra pessoa singular, lhe corresponde de dois modos a razão de mérito ou de demérito. Primeiro, enquanto lhe é devida a retribuição da pessoa singular que ajudou ou ofendeu. Segundo, enquanto lhe é devida a retribuição de todo grupo. - Quando alguém ordena diretamente seu ato para o bem ou mal de todo grupo, lhe é devida a retribuição primeiro e principalmente de todo grupo; em segundo lugar, de todas partes do grupo. - Quando alguém age para seu próprio bem ou mal, também lhe é devida a retribuição enquanto isso reverte para a comunidade, porque é parte do grupo, embora não the seja devida retribuição enquanto é um bem ou mal da pessoa singular que é a mesma que age, a não ser talvez a si mesma, por uma certa semelhança, enquanto existe a justiça do homem para consigo. Conclui-se, pois, que o ato bom ou mau, tem razão de louvável ou de culpável, segundo está sob o poder da vontade; razão de retidão e de pecado, segundo se ordena para o fim; razão de mérito ou de demérito, segundo a retribuição de justiça para o outro (TOMÁS DE AQUINO, $S T, \mathrm{I}^{\mathrm{a}} \mathrm{II}^{\mathrm{ac}}$, q. 21, a. 3, c.).

Com essa resposta, o Mestre de Aquino afirmava o compromisso que os homens teriam perante si e diante do grupo ao qual pertenciam, atrelando-a à virtude da justiça. Em outra parte da obra, ao debater a amizade enquanto parte da justiça, o Aquinate afirmava:

Aristóteles diz: "ninguém consegue passar um dia inteiro com uma pessoa triste e sem atrativos". Por isso o homem é obrigado, por uma espécie de dívida natural de honestidade, a tornar agradáveis as relações com os outros, a menos que, por um motivo particular, seja necessário contristar outros para o próprio bem deles (TOMÁS DE AQUINO, $S T$, $\mathrm{II}^{a} \mathrm{II}^{\mathrm{ac}}$, q. 114, a. 1, ad1m. Grifos nossos). 
Para o Mestre de Aquino, os homens, por sua natureza social, estariam obrigados a agirem bem, a serem agradáveis com os outros homens, mas também, se necessário, a manifestarem-se contra o outro, se esse outro não agisse adequadamente. Em outras palavras, cada homem seria responsável por si, pelo outro e, desse modo, por toda a sociedade.

O Aquinate, entretanto, não deixava a responsabilidade sobre os homens apenas em mãos terrenas. Ao responder ao quarto e último artigo da questão, nomeado "O ato humano enquanto bom ou mau tem razão de mérito ou demérito diante de Deus?" (TOMÁS DE AQUINO, $S T, \mathrm{I}^{\mathrm{a}} \mathrm{II}^{\mathrm{ac}}$, q. 21, a. 4), o autor assegurava que todo ato humano teria razão de mérito ou demérito enquanto se ordenava para a comunidade e, sendo Deus o fim último do homem, todo ato deveria ordenar-se para Deus. Portanto, caberia a Deus também o cuidado com o bem comum e a retribuição dos atos para a comunidade. Com essa elaboração, o autor garantia, por fim, a concórdia entre o céu e a terra.

Retomemos as palavras de Le Goff (1998) em relação ao fato de as Ordens Mendicantes terem sido as primeiras a promover a imagem da cidade e avancemos nesse ponto. Segundo o autor, a reflexão escolástica sobre a cidade repousava numa confusão mais ou menos voluntária, pautada em dois modelos intelectuais (Agostinho e Aristóteles), que foi elaborada na Universidade de Paris (1992, p. 218). Para Le Goff, o principal elaborador da "ideologia urbana" foi o Aquinate:

A ideologia urbana é formulada sobretudo por Tomás de Aquino, que reside em Paris como estudante, depois como licenciado, depois como professor, de 1245 a 1248, de 1252 a 1259, de 1269 a 1272, e seus discípulos, Gilles de Roma [...] e Pierre d'Auvergne [...] (LE GOFF, 1992, p. 218-219).

Quando analisamos a importância que a "comunidade" imprime na elaboração ética de Tomás de Aquino, aproximamo-nos da influência da obra aristotélica no pensamento desse autor. Precisamente por esse motivo, Le Goff afirma: "Aristóteles foi, de certa maneira, o grande homem das universidades do século XIII e, sobretudo, da universidade parisiense" (2007, p. 175). O autor sustenta que somente no século XIII o Ocidente descobriu a metafísica, a ética e a política aristotélicas, obras que atraíam a curiosidade e o desejo dos estudantes e, por volta de 1260 1270 , estavam presentes em quase todo o ensino universitário, tornandose uma moda, sendo possível falar de um "aristotelismo latino medieval". 
Para Le Goff, "Um mestre, que também estava na moda, o dominicano Tomás de Aquino, fora um de seus grandes introdutores nas universidades" (2007, p. 175).

Compreendemos, entretanto, que devemos ser cautelosos ao sugerir um "aristotelismo" em Tomás de Aquino. Quando Tomás de Aquino esteve de volta a Paris - época, segundo Le Goff, da "moda" aristotélica e também da redação do texto que debatemos -, Torrell (1999) sustenta que os adversários enfrentados pelo Aquinate não eram os filósofos do passado, mas seus contemporâneos. Esse autor afirma que a primeira frente de batalha do mestre foi, como dominicano e ao lado dos franciscanos, o combate doutrinal aos seculares em relação à perfeição evangélica da pobreza. Entretanto, o desconforto gerado pelas ideias aristotélicas e interpretações de Averróis gerou conflitos entre os dominicanos e franciscanos e entre os próprios dominicanos (1999, p. 209-228). O Aquinate, durante o período de sua segunda regência em Paris, além de debater com seus pares e lecionar, dedicou-se a comentar a obra aristotélica (TORRELL, 1999, p. 229-261), mas isso não implica fazê-lo aristotélico. O que encontramos ao estudar sua obra é um pensador que, ao olhar para o seu tempo, muniu-se do que havia de mais elaborado, em termos de conhecimento teórico disponível, para analisar a sociedade na qual vivia e, para ela, propor caminhos.

Afirma Lauand, na introdução à sua tradução do texto de magistro do Aquinate:

A antropologia de Tomás - revolucionária para a época - afirma o homem em sua totalidade (espiritual, sim, mas de um espírito integrado à matéria) e está em sintonia com uma teologia (também ela dissonante para a época) que, precisamente para afirmar a dignidade de Deus criador, afirma a dignidade do homem e da criação como um todo: material e espiritual (LAUAND, 2004, p. 6).

Com essas palavras, Lauand sustenta a extensão da elaboração tomasiana que nos leva além da simples consideração de nosso autor como um "aristotélico". Ao debater o pensamento de Aristóteles e contrastá-lo aos pensadores cristãos, o Aquinate pode anunciar um homem cristão que, por assemelhar-se a Deus pela razão, podia constituir-se em sujeito, em animal social, sendo responsável por si e por sua comunidade. 
Le Goff, evocando Ruedi Imach, afirma que Tomás de Aquino entendia o homem como um ser determinado por três relações: com a razão, com Deus e com seu semelhante. Assim "Segundo Tomás, o homem é um homem total. Não é somente uma criatura de Deus, que é um animal racional, mas também um 'animal social e político" (LE GOFF, 2007, p. 188).

Ao debater a questão "As consequências dos atos humanos em razão da bondade e da malícia" (TOMÁS DE AQUINO, ST, I I IIª , q. 21), procuramos compreender a elaboração do Aquinate sobre ética no seio do século XIII. Com efeito, entendemos que ele buscou, no conhecimento acumulado pela humanidade, a base para construir um conhecimento sobre a realidade de sua época. No entanto, gostaríamos aqui de salientar, como parte fundamental da responsabilidade pessoal na construção do bem comum, a importância do ensino. Muito embora, neste texto, não tenhamos selecionado nenhum escrito do autor que o discutisse, entendemos que trouxemos elementos substanciais para essa discussão, que gostaríamos de retomar. Esses elementos dizem respeito à própria atuação de Tomás de Aquino que, enquanto mestre dominicano, responsabilizou-se pelo ensino. Segundo Torrell, a própria motivação para a escrita da Suma de Teologia, que é uma "síntese orgânica" de teologia, parece ter sido a preocupação com a formação dos irmãos da Ordem dos Pregadores (1999, p. 170-171). Nesse sentido, é possível reconhecer em Tomás de Aquino uma responsabilidade que é, ao mesmo tempo, da alçada do conhecimento e do ensino. A própria Suma de Teologia é uma obra pedagógica, pois tem como intenção "educar os educadores", os dominicanos. Virtudes ${ }^{17}$ como amizade, justiça, coragem, honestidade, fundamentais à ética terrestre, são debatidas na obra, ao lado das já consagradas virtudes teologais, fé, esperança e caridade.

Assim Oliveira descreve Tomás de Aquino:

Homem de sua época e, por isso, um dos maiores expoentes do pensamento cristão ocidental do século XIII, não passou ao largo das transformações que a sociedade medieva sofria. Antes, percebendo que os novos valores impostos pelo comércio, pelas cidades e pelo conhecimento das Universidades não permitiram explicações estritamente religiosas das coisas humanas e divinas, buscou nas grandes autoridades do passado a fundamentação teórica necessária para entender e explicar aos homens de seu tempo Deus, a ciência, a razão, o intelecto, o governo dos homens e o pecado, entre outros assuntos. Assim, não por acaso, sua base teórica foi Agostinho e Aristóteles. Ao reto- 
mar as formulações desses dois grandes mestres do conhecimento ocidental, Aquino legitima o poder da Igreja e afirma a importância do homem sobre a terra (OLIVEIRA, 2005, p. 42).

Ao estudarmos a elaboração ética do Mestre de Aquino, especialmente centrada nos atos humanos, mas visando à vida eterna, é notável sua preocupação com as transformações vivenciadas pelos homens do século XIII, fato que nos permite verificar sua preocupação pedagógica em relação à ética, ou seja, à necessidade do conhecimento e do ensino de certas virtudes orientadas para o bem viver, nas novas condições históricas, propostas como condicionantes para se atingir a beatitude. Entretanto, cabe perguntar: se pode - e em que - sua elaboração nos auxiliar no debate ético na atualidade?

Neste sentido, uma pergunta pertinente seria: é ainda defensável, em nível acadêmico, uma ética que encontra seu escopo e sua justificação numa "vida após a morte", numa transcendência tal qual a concebiam os cristãos do século XIII, numa sociedade como a nossa, em que Estado e Igreja são instituições juridicamente distintas e na qual a própria Carta Magna (BRASIL, 1988, art. 5 , VI) possibilita a liberdade irrestrita de crença? Mais pertinente ainda que essa garantia é verificar, no seio da própria lei, qual é o seu escopo:

Art. $3^{\circ}$ Constituem objetivos fundamentais da República Federativa do Brasil: I - construir uma sociedade livre, justa e solidária;

II - garantir o desenvolvimento nacional;

III - erradicar a pobreza e a marginalização e reduzir as desigualdades sociais e regionais;

IV - promover o bem de todos, sem preconceitos de origem, raça, sexo, cor, idade e quaisquer outras formas de discriminação (BRASIL, 1988, art. $3^{\circ}$ ).

Ao observarmos os objetivos fundantes de nossa Carta Magna, quanto ao primeiro sentido proposto, compreendemos que a resposta é certamente negativa, visto que não apenas a liberdade de crença impede a imposição de determinada religiosidade sobre as demais, como, neste caso, uma religiosidade cristã católica, mas também, e principalmente, porque os alvos de nossas leis restringem-se a conteúdos laicos. Há, entretanto, outra forma de se considerar a questão, que não implica, de nenhuma maneira, a defesa da "verdade" tomasiana, mas, ao contrário, a compreensão do tratamento que esse intelectual dispensou ao tema, questio- 
nando o conhecimento estabelecido e utilizando nessa empreitada um autor anterior ao próprio cristianismo. Trazer um autor pagão para junto da experiência material vivenciada pelos homens de seu tempo e da concepção teórica estabelecida pela tradição cristã permitiu que Tomás de Aquino formulasse, do ponto de vista teórico, uma totalidade do homem, contra uma ruptura que parecia se impor. Sem dúvida, o Aquinate adaptou Aristóteles à filosofia cristã, o que, no entanto, lhe permitiu integrar perfeitamente filosofia e teologia, num conhecimento sistemático e de tipo novo.

Muito embora não tenhamos analisado explicitamente o debate sobre a ética na contemporaneidade, mas apenas considerado a Carta Magna, esta se configura como salutar por ter sido estabelecida como resultado de um amplo debate ético. Ela nos permite considerar que, do ponto de vista acadêmico, é evidente que ao debate se impõe a laicidade, ao considerarmo-lo de maneira mais universal, visto que o bem-comum não se refere a um ideal posto fora da vida material. A pergunta mais coerente por este ângulo seria: em que medida estudar a obra de um intelectual da filosofia-teologia cristã medieval pode nos auxiliar a formular mais explicitamente nossas questões éticas e a buscar para ela respostas exclusivamente laicas?

\section{Considerações finais}

Consideramos de suma importância, para as reflexões que vinculam o debate entre ética e educação nos dias atuais, retomar os escritos tomasianos, porque nossos debates podem ser enriquecidos com a contribuição desse mestre. Essa relevância incide no fato de que o autor não se esquivou dos problemas de seu tempo e procurou elaborar um conhecimento teórico que contribuísse para o bem viver dos homens na sociedade cristã do século XIII. A exemplo de Tomás de Aquino, é imperativo que debatamos nossas próprias questões históricas e, dessa forma, nos apropriemos do conhecimento teórico que acumulamos, não apenas em nossa produção teórica, mas também em nossos atos pedagógicos cotidianos, pois são estes atos que podem educar a comunidade escolar/universitária para novos caminhos. 
Concordamos com Tomás de Aquino quanto a sermos animais sociais e, embora nossas condições políticas, econômicas e intelectuais sejam bastante distintas daquelas do contexto no qual ele produziu a sua obra, ainda somos citadinos. Nossa referência existencial são as cidades, em toda a complexidade de relações que elas nos impõem. Falar de bem comum em nosso tempo é refletir sobre os direitos e deveres, valores que precisam ser exercitados e ensinados, se realmente temos o ideal do bem viver em sociedade (OLIVEIRA, 2008; OLIVEIRA, 2010). Evidentemente que se estivéssemos somente em busca do animal social, citadino, poderíamos nos esquivar do medievo e estudar, por exemplo, o próprio Aristóteles, visto que suas preocupações éticas se referiam, com exclusividade, à sociedade material. Mas se estivermos dispostos a questionar - e mesmo superar - nossas verdades instituídas, é salutar considerarmos também a tradição cristã, ao menos seus mestres mais influentes, não apenas para nos certificarmos do que é novo e do que remete a um tempo mais longo em nossas escolas de pensamento, mas também para que possamos nos apropriar da experiência humana em repensar hábitos e atitudes, tendo em vista ideais sociais. Tomás de Aquino é um dos autores que nos ensina essa abertura à totalidade do conhecimento, bem como a responsabilidade intelectual que nos é imputada quando estudamos, refletimos e agimos em sintonia com um projeto mais amplo: o de sermos partícipes do bem comum da nossa comunidade/sociedade. 


\section{Referências}

BRASIL. Constituição da República Federativa do Brasil de 1988. Brasília: Casa Civil, $1988 . \quad$ Disponível em: <http://www.planalto.gov.br/ccivil_03/Constituicao/Constituicao.htm>. Acesso em: 8 dez. 2011.

CRISP, R. Moiralidade [verbete]. In: OUTHWAITE, W.; BOTTOMORE, T. (Ed.). Dicionário do pensamento social no século XX. Rio de Janeiro: Jorge Zahar, 1996, p. 483484.

GRABMANN, M. Introdução à Suma Teológica de Santo Tomás de Aquino. Petrópolis; Rio de Janeiro; São Paulo, Vozes, 1944.

KENNY, A.; PINBORG, J. Medieval philosophical literature. In: KRETZMANN, N.; KENYY, A.; PINBORG, J. (Ed.). The Cambridge History of Late Medieval Philosophy: from the rediscovery of Aristotle to the disintegration of Scholasticism, 1100-1600. Cambridge: Cambridge University Press, 1997, p. 11-42.

LAUAND, L. Estudos introdutórios. In: TOMÁS DE AQUINO. Sobre o ensino (De magistro), os sete pecados capitais. 2 ed. São Paulo: Martins Fontes, 2004. p. 3-22.

LAUAND, L. Estudos introdutórios e notas. In: TOMÁS DE AQUINO. Verdade e Conhecimento. São Paulo: Martins Fontes, 1999. p. 1-80; p. 387-390.

LE GOFF, J. As raizes medievais da Europa. 2 ed. São Paulo: Vozes, 2007.

LE GOFF, J. Os intelectuais na Idade Média. 2 ed. Rio de Janeiro: José Olympio, 2006.

LE GOFF, J. A civilização no Ocidente Medieval. Bauru: Edusc, 2005.

LE GOFF, J. A bolsa e a vida. São Paulo: Brasiliense, 2004.

LE GOFF, J. Por amor às cidades. São Paulo: Editora Unesp, 1998.

LE GOFF, J. O apogeu da cidade medieval. São Paulo: Martins Fontes, 1992.

OLIVEIRA, T. Universidade e Cultura na ambiência citadina do século XIII: um olhar sobre os mestres Tomás de Aquino e Boaventura de Bagnoregio. In: OLIVEIRA, T. (Org.) História e Historiografia da Educação nos Clássicos: estudos sobre antiguidade e medievo. Dourados: Ed. da UEMS, 2010, p. 261-304.

OLIVEIRA, T. O ambiente citadino e universitário do século XIII: lócus de conflitos e de novos saberes. In: OLIVEIRA, T (Org.) Antiguidade e Medievo. Olhares Histórico-filosóficos da Educação. Maringá: Eduem, 2008, p. 227-250.

O’NEIL, J. Ética [verbete]. In: OUTHWAITE, W.; BOTTOMORE, T. (Ed). Dicionário do pensamento social no século XX. Rio de Janeiro: Jorge Zahar, 1996, p. 278280.

PATEMAN, T. Educação e teoria social [verbete]. In: OUTHWAITE, W.; BOTTOMORE, T. (Ed.). Dicionário do pensamento social no século XX. Rio de Janeiro: Jorge Zahar, 1996, p. 233-235.

PATEMAN, T. Escolástica. São Paulo/Porto: Mandruvá/Univ. do Porto, 2005.

TOMÁS DE AQUINO. A amizade ou afabilidade (ST, II $\mathrm{II}^{\text {ae }}$, q. 114). In: TOMÁS DE AQUINO. Suma Teológica. São Paulo: Loyola, 2004, v. VI, p. 642-646.

TOMÁS DE AQUINO. As consequências dos atos humanos em razão da bondade e da malícia (ST, I I II ${ }^{\text {ac }}$, q. 21). In: TOMÁS DE AQUINO. Suma Teológica. São Paulo: Loyola, 2003, v. III, p. 290-298.

TOMÁS DE AQUINO. A existência de Deus (ST, I ${ }^{a}$, q. 2). In: TOMÁS DE 
AQUINO. Suma Teológica. São Paulo: Loyola, 2001, v. I, p. 161-169.

TORRELL, J.-P. Iniciação a Santo Tomás de Aquino: sua pessoa e sua obra. São Paulo: Loyola, 1999.

VERGER, J. Cultura, ensino e sociedade no Ocidente nos séculos XII e XIII. Bauru: Edusc, 2001.

VERGER, J. Homens e saber na Idade Média. Bauru: Edusc, 1999. 


\section{Notas}

1 O renascimento das cidades foi parte de um conjunto de profundas transformações que ocorreram no Ocidente medieval, a partir do Ano Mil. Pela complexidade dessas transformações não nos cabe discuti-las neste artigo, uma vez que nos afastaria de nosso objetivo. Todavia, indicamos a leitura de dois textos que explicitam essas mudanças históricas. O primeiro se intitula "O ambiente citadino e universitário do século: lócus de conflitos e novos saberes" (OLIVEIRA, 2008) e o segundo "Universidade e Cultura na ambiência citadina do século XIII: um olhar sobre os mestres Tomás de Aquino e Boaventura de Bagnoregio" (OLIVEIRA, 2010). Consultar referências bibliográficas.

2 A pergunta "como devo agir?" remete às éticas de origem kantiana, dado que se pressupõe que os princípios éticos são universais, enquanto a pergunta "que tipo de pessoa eu quero ser?” remete às éticas de inspiração aristotélica. O’Neill (1996) afirma que esta última forma de pensar a ética tem sido retomada, na atualidade, por autores de inspiração aristotélica, entretanto não os nomeia.

3 Sabemos que a norma para a referência em citação obedece ao padrão: (AUTOR, data da publicação utilizada, página); entretanto, para textos medievais utilizamos: (AUTOR, sigla da obra, localização da citação no interior da obra).

4 O nome mais antigo da obra é Summa Theologiae (Suma de Teologia). Hoje a obra é mais referenciada por Summa Theologica (Suma Teológica), entretanto, essa forma é mais recente e teve menor frequência na literatura medieval (TORRELL, 1999). Por esse motivo, preferimos utilizar o nome Suma de Teologia, ainda que a tradução mais recente da obra para a língua portuguesa nomeie-a de Suma Teológica.

5 Le Goff não é especialista em Tomás de Aquino. Entretanto, ao propormos uma discussão que se pautasse principalmente nesse autor, o fizemos porque Le Goff privilegia a análise da cidade medieval em diversos textos, espaço essencial para a universidade e seus mestres.

6 Aquinate, Mestre de Aquino, Mestre Tomás, Doutor Angélico são formas de tratamento que designam Tomás de Aquino e sua obra, convencionadas pela bibliografia especializada no autor.

7 No século XIII e por muito tempo depois, a maioria da população do que veio a se tornar "Europa" habitava os campos. Sabemos que muitas relações sociais persistiram nos moldes feudais até pelo menos a época da Revolução Francesa e que as cidades não foram ilhas independentes. No entanto, consideramo-las como espaços privilegiados do processo de transformação social.

8 Segundo Le Goff, “Um documento excepcional diz respeito às corporações parisienses na segunda metade do século XIII, no final do reinado de São Luís. É a coletânea de estatutos de ofício - com a exceção, notável, dos açougueiros — que o preboste real de Paris, Étienne Boileau, fez redigir para fins de controle e vigilância por volta de 1268. Esse registro, do qual apenas possuímos cópias, entre elas uma contemporânea do original, denominava-se L'Establissement des mestiers de Paris e é conhecido sob o nome de Livre des métiers (Livro dos ofícios). Os cento e um ofícios cujas regulamentações ele fornece 
sob diversas formas — o que testemunha a divisão extremamente minuciosa do trabalho segundo as diferentes operações técnicas de fabricação e segundo os diversos objetos fabricados e vendidos [...]” (LE GOFF, 1992, p. 105).

9 Segundo Le Goff (2007), dois modelos de corporação universitária foram instituídos na Idade Média: o parisiense e o bolonhês, sendo que só o primeiro chegou aos dias de hoje. Segundo o mesmo autor, a primeira universidade foi a de Bolonha, que, embora tenha recebido seus primeiros estatutos do Papa somente em 1252, desde 1154 conseguira privilégios do imperador. Já a Universidade de Paris obteve privilégios papais em 1174 e do rei em 1200, mas só recebeu o estatuto do legado pontifício em 1215 e a bula Parens scientiarum em 1231. Não temos, nesse trabalho, a intenção de discutir o modelo bolonhês, nem o nascimento da instituição naquela cidade. Para maiores detalhes, consultar: VERGER, J. As universidades na Idade Média. São Paulo: Editora da Unesp, 1990.

10 Le Goff afirma "mais ou menos" uma vez que diversas ordens não monásticas surgiram no século XIII e o papado tratou de controlar o movimento, reduzindo-as a apenas quatro, em 1274, no Segundo Concílio de Lyon: os Pregadores (conhecidos por Dominicanos ou Jacobinos), os Menores (Franciscanos ou Cordeliers), os Agostinianos e os Carmelitas (LE GOFF, 1992, p. 46).

11 A disseminação dessas ordens foi grande: “Com o auxílio do catálogo dos conventos mendicantes da França medieval de Richard W. Emery, foi possível localizar 423 conventos fundados entre o início dos anos 1210-1220 e 1275, 215 entre 1275 e 1350" (LE GOFF, 1992, p. 54).

12 Le Goff afirma que as cidades importantes do Ocidente medieval possuíam em torno de 10 a 20 mil habitantes e apenas algumas tinham um número bem superior, sendo a maior, incontestavelmente, Paris, que, por volta de 1300, tinha, "sem dúvida", 200 mil habitantes (LE GOFF, 2007, p. 147).

13 O terceiro período apontado por Le Goff é posterior à morte de Tomás de Aquino. 14 O conflito entre seculares e mendicantes pelos rumos que a instituição deveria tomar foi complexo e teve alguns picos. Por esse motivo, não nos cabe tratar detalhadamente dele neste trabalho. Grosso modo, começou com a opção da corporação por uma greve em defesa de seus direitos (1229-1231), que não foi acatada pelos mendicantes e durante a qual foi outorgada a primeira licença de teologia para um dominicano. A partir de então, em diferentes situações, os seculares acusavam os mendicantes de não se integrarem à universidade, pois privilegiavam a própria regra e colocavam em risco a autonomia da corporação. Na questão doutrinal, conflitaram principalmente em relação ao lugar que se deveria conceder aos estudos de Aristóteles. Para um acesso inicial à discussão, consultar, entre outros: CAVALCANTE, T. M. A corporação de mestres e estudantes de Paris, foco privilegiado das relações de poder. In: CAVALCANTE, T. M. Aspectos educacionais da obra de Santo Tomás de Aquino no contexto escolástico-universitário do século XIII. 2006. Dissertação (Mestrado em Educação) Programa de Pós-Graduação em Educação, Universidade Estadual de Campinas, 2006. p. 55-79.

15 Artes se referem à divisão do conhecimento: Artes Liberais e, desde o século XII, também as Mecânicas. 
16 A referência às categorias profissionais é reincidente nos textos formulados no século XIII: "A nova palavra das ordens mendicantes, pronunciada do púlpito ou na praça, dirige-se muitas vezes a esta ou aquela categoria socioprofissional e leva amplamente em conta a nova sociedade urbana. São os sermones ad status ('sermões aos estados do mundo'), atentos aos pecados considerados específicos de cada categoria, consignando a constituição de novos grupos sociais, como outras tantas comunidades pecadoras, a serem salvas em comum" (LE GOFF, 1992, p. 190).

17 Por sua complexidade, este trabalho não objetiva esmiuçar essas virtudes, objeto da segunda parte da obra tomasiana, mas apontar a relevância do conhecimento e do ensino de virtudes terrestres.

Recebido: 14/01/2011

Aprovado: 21/12/2012

Contato:

Rua Lúcia Helena Zampieri, 100

Jardim Boa Esperança

CEP $13091-525$

Campinas, SP

Brasil 
